\title{
Dynamic evolution of a hydraulic-mechanical- electric system with randomly fluctuating speed
}

\author{
Beibei Xu' ${ }^{\mathrm{a}}$, Diyi Chen*a,b ${ }^{* a}$ Xiang Gao ${ }^{\mathrm{a}}$, Caraballo, Tomas ${ }^{\mathrm{c}}$, Edoardo Patelli ${ }^{\mathrm{d}}$ \\ ${ }^{a}$ Institute of Water Resources and Hydropower Research, Northwest A\&F \\ University, Shaanxi Yangling 712100, P. R. China \\ ${ }^{b}$ Key Laboratory of Agricultural Soil and Water Engineering in Arid and \\ Semiarid Areas, Ministry of Education, Northwest A \& F University, Shaanxi \\ Yangling 712100, P. R. China \\ 'Depto. Ecuaciones Diferenciales y Análisis Numérico, Facultad de Matemáticas, \\ Universidad de Sevilla, c/ Tarfia s/n, E-41012 Sevilla, Spain \\ ${ }^{d}$ Institute for Risk and Uncertainty, Chadwick Building, University of Liverpool, \\ Peach Street, Liverpool L69 7ZF, United Kingdom \\ Corresponding author: Diyi Chen
}

Mailing Address: Institute of Water Resources and Hydropower Research, Northwest A\&F University, Shaanxi Yangling 712100, China

Telephones: 086-181-6198-0277

E-mail: diyichen@nwsuaf.edu.cn

Abstract The generator speed is an important index in maintaining the stable connection between the hydraulic turbine and the electric power system. Historically, researches carried out are based on deterministic models. It is therefore a challenge to investigate the effects of random fluctuating speed on the dynamic evaluation of the hydraulic-mechanical-electric system as variable renewable generation sources link to the electric power system. Here, we proposed a probabilistic model and solved it by the Chebyshev polynomial approximation method. We also performed a careful comparison implemented by the deterministic and the probabilistic models. Finally, we showed how the random excitations affect the dynamic evaluation of the system output.

Key words: vibration characteristics; hydraulic-mechanical-electrical system; randomly fluctuating generator speed; elastic water hammer; Chebyshev polynomial approximation;

\section{Introduction}

Over the last decades, the hydropower sector has experienced a rapid development in China, with the constructions of power stations in every corner of the country, reaching an installed capacity of ten hundred million kilowatts [1-4]. The construction of new hydropower installations will be promoted to double the worldwide installed capacity within the next thirty years $[5,6]$ according to the 
2014 plan agreed by most international hydropower industries. The reliability and safety of such installations have nourished the concerns of the public opinion as well as of the regulators [7-12] due to this rapid expansion. In particular, the hydraulic-mechanical-electrical system is a crucial component which plays an essential role for the safety of individual installations and can hence affect the stability of the whole electric power grid. Therefore, the analysis of the stability of hydraulic-mechanical-electric systems is a high-priority topic of research. Studies focusing on hydraulic-mechanical-electric systems can be roughly classified in two groups. The first focuses on the grid water hammer theory, aiming at establishing deterministic models for the hydraulic-mechanical-electric system [13-18]. This approach is suitable to describe the dynamic evolution of the system with short penstocks characterized by uniform geometry. The works belonging to the second group adopt the elastic water hammer theory [19-27]. This approach is used to accurately analyze the dynamic characteristics of the system with long penstocks and allows to take into account eventual shape changes in the geometry of the penstock.

As highlighted by the last Global Wind Energy Outlook, the wind power sector has grown rapidly over the last decades in terms of both technological and commercial competitiveness: this is expected to result in an installed capacity of nearly 2 TW by 2030, supplying between $16.7 \%$ and $18.8 \%$ of global electricity [34]. Obviously, this trend may potentially affect the stability of power grids, leading to larger random fluctuations of hydro-turbine generators speed [35-38]. The generator speed is an important index in maintaining the stable connection between the hydraulic turbine and the electric power system. Its fluctuation interval directly decides whether the load rejection occurs in failure the hydraulic turbine. As we all know, the hydraulic-mechanical-electric system has complex nonlinear, time-variant and non-minimum phase, which is not only the response affected by the external factors but also a typical nonlinear response caused by the internal instability factors. For a long time, fluctuation of generator speed focused on the components of hydraulic-mechanical-electric system, ignoring the interaction effect of these components and the unstable behaviors caused by this effect. Therefore, it provides a novel insight to study the interaction effect and the unstable behaviors caused by this effect from nonlinear dynamics. In addition, as time goes by, in the subsystems of hydraulic-mechanical-electric system will 
inevitably appear such phenomena as equipment aging, unit vibration and noise increasing, etc. From the perspective of nonlinear dynamics, it is considered as the variation of the structural parameters and performance parameters in the subsystems, leading to the deterioration of the service performance. Obviously, the nonlinear dynamic evolution of the system becomes the main reason. This provides a novel insight to study the deterioration of the service performance from nonlinear dynamic evolution. Furthermore, regarding the uncertainties, hydropower stations will run for a long time as planned in construction, which will gradually cause the value change of hydraulic, mechanic or electric parameters. Therefore, we conclude the following two fundamental problems. First, whether the operating stability of these units will be changed in the next thirty or forty years? Second, can we predict the dynamic evolution of the system caused by the uncertainties of model parameters? As we all know, the aim of the sensitivity analysis is an attempt to investigate the effect of parametric uncertainty on the system output. Hence, we can obtain major contribution parameters affecting the values of system output from the sensitivity analysis, which not only provides guidance for model validation but also helps to seek key parameters causing the change of dynamic evolution of the hydraulic-mechanical-electric system.

In light of the above analysis, our work proposes a novel approach to the stability analysis of the hydraulic-mechanical-electric system with respect to the existing literature. First, a probabilistic component $u$ is integrated with the generator speed $\omega$, obtaining a novel probabilistic model of the hydraulic-mechanical-electric system. Second, the sensitivity analysis is performed based on the probabilistic model. Third, the advantages and drawbacks of each method are identified comparing the dynamic evolutions of the deterministic and probabilistic approaches. Fourth, a mathematical definition of the differential gain $\mathrm{k}_{\mathrm{d}}$ is proposed for the PID in terms of a function of the fluctuation intensity D. Finally, the consistence of such definition is verified through a numerical application. The content of this paper is organized as follows: Section 2 presents the nonlinear probabilistic model of the hydraulic-mechanical-electric system. Numerical simulations along with detailed analysis of the results obtained are presented in Section 3. Conclusive remarks and discussions are included in Section 4. 


\section{Mathematical modeling and sensitivity method}

\subsection{Mathematical modeling}

The hydraulic-mechanical-electric system is shown in Eq. (1) considering the elastic water hammer model adopted in this study:

$$
\left\{\begin{array}{l}
\dot{x}_{1}=x_{2} \\
\dot{x}_{2}=x_{3} \\
\dot{x}_{3}=-a_{0} x_{1}-a_{1} x_{2}-a_{2} x_{3}+y \\
\dot{\delta}=\omega_{s} \omega \\
\dot{\omega}=\frac{1}{T_{a b}}\left[m_{t}-\frac{E_{q}^{\prime} V_{s}}{x_{d \Sigma}^{\prime}} \sin \delta-\frac{V_{s}^{2}}{2} \frac{x_{d \Sigma}^{\prime}-x_{q \Sigma}}{x_{d \Sigma}^{\prime} x_{q \Sigma}} \sin 2 \delta-D_{t} \omega\right](1) \\
\dot{y}=\frac{1}{T_{y}}\left(k_{p}(r-\omega)+k_{i} x_{4}-k_{d} \dot{\omega}-y\right) \\
\dot{x}_{4}=r-\omega
\end{array}\right.
$$

Details about the parameters in Eq. (1) can be found in Ref. [26].

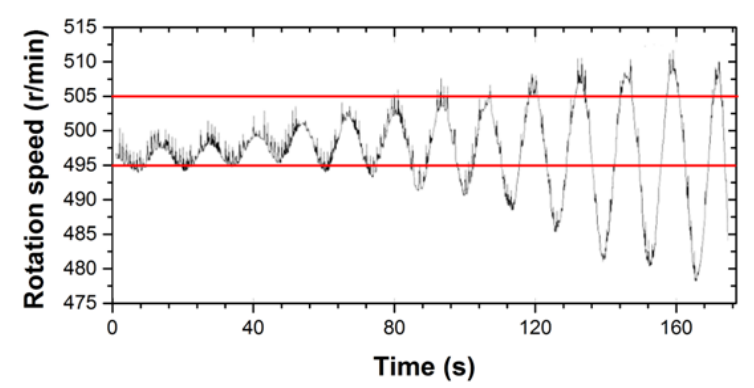

Fig. 1 Rotation speed versus time. Red lines are the upper-lower limits of the electric power system regarding the rotation speed. Black line is the actual fluctuation of the rotation speed. It indicates that a load rejection failure would happen when the value of the rotation speed exceeds the upper-lower limits.

Two different types can be identified from Fig. 1. The first refers to a limited range, of about 495 505 r/min for values of time $t$ lower than $120 \mathrm{~s}$. This type of fluctuation is difficult to detect from the generator running sound due to the negligibility of the associated noise compared to that of the operating environment. The second type refers to fluctuations within the range 49.5 50.5 r/ min, as shown in Fig. 1 for time values $t$ higher than $120 \mathrm{~s}$. Both types of identified fluctuation have the potential to break the dynamic balance of torques between the hydro-turbine and the generator. In light of this, a probabilistic representation of the torque caused by the speed fluctuation is essential to obtain the state-space representation of the generator speed. Let $D u \omega$ be the random torque, then the generator speed can be written as: 


$$
\dot{\omega}=\frac{1}{T_{a b}}\left[m_{t}-\frac{E_{q}^{\prime} V_{s}}{x_{d \Sigma}^{\prime}} \sin \delta-\frac{V_{s}^{2}}{2} \frac{x_{d \Sigma}^{\prime}-x_{q \Sigma}}{x_{d \Sigma}^{\prime} x_{q \Sigma}} \sin 2 \delta-D_{t} \omega-D u \omega\right]
$$

where $u$ is the random variable introduced in this study. Its probability density function, shown in Fig. 2, can be described as [39]

$$
p(u)=\left\{\begin{array}{cc}
\frac{2}{\pi} \sqrt{1-u^{2}} ; & |u| \leq 1 . \\
0 ; & |u|>1 .
\end{array}\right.
$$

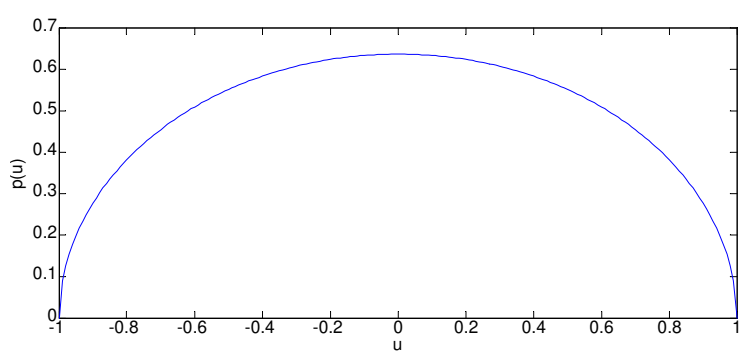

Fig. 2 The probability density function $p(u)$ versus random variable $u$. It indicates that the closer value of variable $u$, the greater probability.

The Chebyshev polynomial approximation is used to simplify the probabilistic model of the hydraulic-mechanical-electric system. Such approximation can be presented as:

$$
U_{n}(u)=\sum_{k=0}^{\frac{n}{2}} \frac{(-1)^{k}(n-k) !}{k !(n-2 k) !}(2 u)^{n-2 k}
$$

From Eq. (4), the following equations can be obtained as

$$
\left\{\begin{array}{l}
U_{0}=1 \\
U_{1}=2 u \\
U_{2}=4 u^{2}-1 \\
U_{3}=8 u^{3}-4 u \\
U_{4}=16 u^{4}-12 u^{2}+1 \\
\cdots
\end{array} .\right.
$$

Its recurrence relation is

$$
n U_{n}(u)=\frac{1}{2}\left[U_{n-1}(u)+U_{n+1}(u)\right],
$$

and the approximation property is

$$
\int_{1}^{1} \frac{2}{\pi} \sqrt{1-u^{2}} U_{i}(u) U_{j}(u) d u= \begin{cases}1, & i=j \\ 0, & i \neq j\end{cases}
$$

Based on Eq. (4), the function $f(u)$ can be expanded as: 


$$
f(u)=\sum_{i=0}^{\infty} c_{i} U_{i}(u)
$$

where $c_{i}=\int_{1}^{l} p(u) f(u) U_{i}(u) d u$.

According to the approximation theory of orthogonal polynomials and the above analysis, the random variables of the hydraulic-mechanical-electric system can be written as

$$
\left\{\begin{array}{l}
x_{1}(t, u)=\sum_{i=0}^{N} x_{1(i)}(t) U_{i}(u) \\
x_{2}(t, u)=\sum_{i=0}^{N} x_{2(i)}(t) U_{i}(u) \\
x_{3}(t, u)=\sum_{i=0}^{N} x_{3(i)}(t) U_{i}(u) \\
\delta(t, u)=\sum_{i=0}^{N} \delta_{(i)}(t) U_{i}(u) \\
\omega(t, u)=\sum_{i=0}^{N} \omega_{(i)}(t) U_{i}(u) \\
y(t, u)=\sum_{i=0}^{N} y_{(i)}(t) U_{i}(u) \\
x_{4 i}(t)=\sum_{i=0}^{N} x_{4 i}(t) U_{i}(u)
\end{array}\right.
$$

where $N$ is the maximum number of Chebyshev polynomials;

$$
\begin{aligned}
& x_{1(i)}(t)=\int_{1}^{+1} p(u) x_{1}(t, u) U_{i}(u) d u ; x_{2(i)}(t)=\int_{1}^{+1} p(u) x_{2}(t, u) U_{i}(u) d u ; \\
& x_{3(i)}(t)=\int_{1}^{+1} p(u) x_{3}(t, u) U_{i}(u) d u ; \delta_{i}(t)=\int_{1}^{+1} p(u) \delta(t, u) U_{i}(u) d u ; \omega_{i}(t)=\int_{1}^{+1} p(u) \omega(t, u) U_{i}(u) d u ; \\
& y_{i}(t)=\int_{1}^{+1} p(u) y(t, u) U_{i}(u) d u ; x_{4 i}(t)=\int_{1}^{+1} p(u) x_{4 i}(t, u) U_{i}(u) d u .
\end{aligned}
$$

In light of this, the random state-space equations of the hydraulic-mechanicalelectric system can be rewritten as:

$$
\left\{\begin{array}{l}
\frac{d}{d t}\left[\sum_{i=0}^{N} x_{1(i)}(t) U_{i}(u)\right]=\sum_{i=0}^{N} x_{2(i)}(t) U_{i}(u) \\
\frac{d}{d t}\left[\sum_{i=0}^{N} x_{2(i)}(t) U_{i}(u)\right]=\sum_{i=0}^{N} x_{3(i)}(t) U_{i}(u) \\
\frac{d}{d t}\left[\sum_{i=0}^{N} x_{3(i)}(t) U_{i}(u)\right]=-a_{0} \sum_{i=0}^{N} x_{1(i)}(t) U_{i}(u)-a_{1} \sum_{i=0}^{N} x_{2(i)}(t) U_{i}(u)-a_{2} \sum_{i=0}^{N} x_{3(i)}(t) U_{i}(u)+\sum_{i=0}^{N} y_{(i)}(t) U_{i}(u) \\
\frac{d}{d t}\left[\sum_{i=0}^{N} \delta_{(i)}(t) U_{i}(u)\right]=\omega_{s} \sum_{i=0}^{N} \omega_{(i)}(t) U_{i}(u) \\
\frac{d}{d t}\left[\sum_{i=0}^{N} \omega_{(i)}(t) U_{i}(u)\right]=\frac{1}{T_{a b}}\left[m_{t}-P_{e}^{\prime}-\left(D_{t}+D u\right) \sum_{i=0}^{N} \omega_{(i)}(t) U_{i}(u)\right] \\
\frac{d}{d t}\left[\sum_{i=0}^{N} y_{(i, j}(t) U_{i}(u)\right]=\frac{1}{T_{y}}\left(k_{p}\left(r-\sum_{i=0}^{N} \omega_{(i)}(t) U_{i}(u)\right)+k_{i} \sum_{i=0}^{N} x_{4(i)}(t) U_{i}(u)-k_{d} \frac{d}{d t}\left[\sum_{i=0}^{N} \omega_{(i)}(t) U_{i}(u)\right]-\sum_{i=0}^{N} y_{(i,)}(t) U_{i}(u)\right) \\
\frac{d}{d t}\left[\sum_{i=0}^{N} x_{4(i)}(t) U_{i}(u)\right]=r-\sum_{i=0}^{N} \omega_{(i)}(t) U_{i}(u)
\end{array}\right.
$$


where $P_{e}^{\prime}=\frac{E_{q}^{\prime} V_{s}}{x_{d \Sigma}^{\prime}} \sin \left[\sum_{i=0}^{N} \delta_{(i)}(t) U_{i}(u)\right]-\frac{V_{s}^{2}}{2} \frac{x_{d \Sigma}^{\prime}-x_{q \Sigma}}{x_{d \Sigma}^{\prime} X_{q \Sigma}} \sin 2\left[\sum_{i=0}^{N} \delta_{(i)}(t) U_{i}(u)\right]$.

Combining these expressions, $D u(t)\left[\sum_{i=0}^{N} \omega_{(i)}(t) U_{i}(u)\right]$ is simplified as:

$$
D u(\mathrm{t})\left[\sum_{i=0}^{N} \omega_{(i)}(t) U_{i}(u)\right]=\frac{1}{2} D \sum_{i=0}^{N} \omega_{(i)}(t)\left[U_{i-1}(u)+U_{i+1}(u)\right]=\frac{1}{2} D \sum_{i=0}^{N}\left[\omega_{(i-1)}(t)+\omega_{(i+1)}(t)\right] U_{i}(u)
$$

where $\omega_{-1}=0$, and $\omega_{N+1}=0$.

Replacing Eq. (9) into Eq. (8), the probabilistic model of the system is written as:

$$
\begin{aligned}
& \int \frac{d}{d t}\left[\sum_{i=0}^{N} X_{1(i)}(t) U_{i}(u)\right]=\sum_{i=0}^{N} X_{2(i)}(t) U_{i}(u) \\
& \frac{d}{d t}\left[\sum_{i=0}^{N} x_{2(i)}(t) U_{i}(u)\right]=\sum_{i=0}^{N} x_{3(i)}(t) U_{i}(u) \\
& \frac{d}{d t}\left[\sum_{i=0}^{N} x_{3(i)}(t) U_{i}(u)\right]=-a_{0} \sum_{i=0}^{N} x_{1(i)}(t) U_{i}(u)-a_{1} \sum_{i=0}^{N} x_{2(i)}(t) U_{i}(u)-a_{2} \sum_{i=0}^{N} x_{3(i)}(t) U_{i}(u)+\sum_{i=0}^{N} y_{(i)}(t) U_{i}(u) \\
& \left\{\frac{d}{d t}\left[\sum_{i=0}^{N} \delta_{(i)}(t) U_{i}(u)\right]=\omega_{s} \sum_{i=0}^{N} \omega_{i j}(t) U_{i}(u)\right. \\
& \frac{d}{d t}\left[\sum_{i=0}^{N} \omega_{i j}(t) U_{i}(u)\right]=\frac{1}{T_{a b}}\left[m_{t}-P_{e}-D_{t} \sum_{i=0}^{N} \omega_{(i)}(t) U_{i}(u)-\frac{1}{2} D \sum_{i=0}^{N}\left[\omega_{(i-1)}(t)+\omega_{(i+1)}(t)\right] U_{i}(u)\right] \\
& \frac{d}{d t}\left[\sum_{i=0}^{N} y_{(i)}(t) U_{i}(u)\right]=\frac{1}{T_{y}}\left(k_{p}\left(r-\sum_{i=0}^{N} \omega_{(i)}(t) U_{i}(u)\right)+k_{i} \sum_{i=0}^{N} x_{4(i)}(t) U_{i}(u)-k_{d} \frac{d}{d t}\left[\sum_{i=0}^{N} \omega_{(i)}(t) U_{i}(u)\right]-\sum_{i=0}^{N} y_{(i)}(t) U_{i}(u)\right) \\
& \frac{d}{d t}\left[\sum_{i=0}^{N} X_{4(i)}(t) U_{i}(u)\right]=r-\sum_{i=0}^{N} \omega_{i j}(t) U_{i}(u)
\end{aligned}
$$

Multiply the above system of equations by $U_{i}(u)$. the initial probabilistic model can be approximated by the system in Eq. (11) considering the mathematical expectation with regard to the random variable $u$ on both sides of Eq. (10), and setting $i=0,1,2,3$, and 4 : 


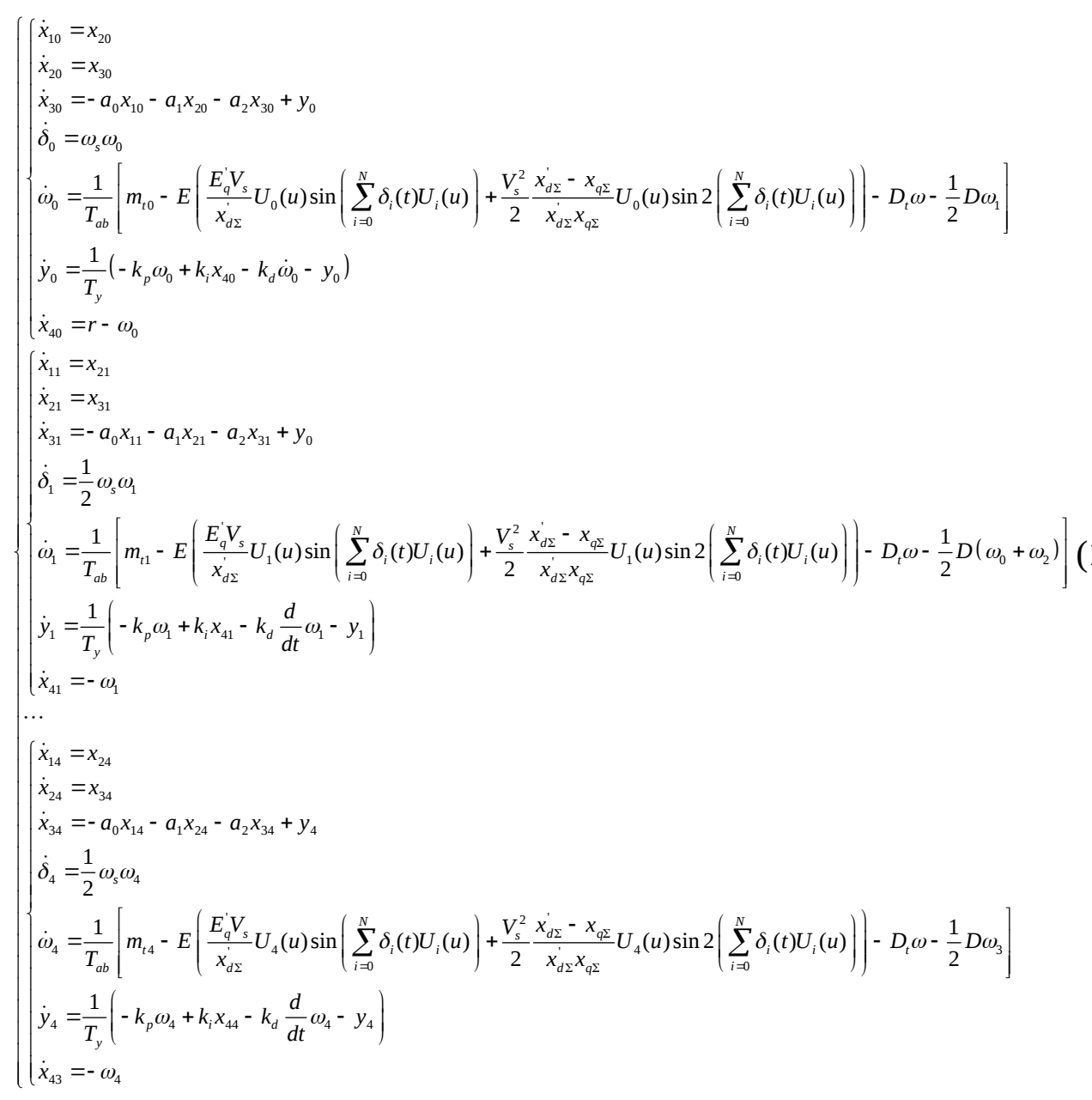

The formula of the mathematical expectation of the electromagnetic torque $P_{e}^{\prime}$ is then written as:

$$
\begin{aligned}
E\left[P_{e}^{\prime}\right] & =E\left(\frac{E_{q}^{\prime} V_{s}}{x_{d \Sigma}^{\prime}} \sin \left[\sum_{i=0}^{N} \delta_{(i)}(t) U_{i}(u)\right]-\frac{V_{s}^{2}}{2} \frac{x_{d \Sigma}^{\prime}-x_{q \Sigma}}{x_{d \Sigma}^{\prime} X_{q \Sigma}} \sin 2\left[\sum_{i=0}^{N} \delta_{(i)}(t) U_{i}(u)\right]\right) \\
& =\int_{1}^{1}\left(\frac{E_{q}^{\prime} V_{s}}{x_{d \Sigma}^{\prime}} \sin \left[\sum_{i=0}^{4} \delta_{(i)}(t) U_{i}(u)\right]-\frac{V_{s}^{2}}{2} \frac{x_{d \Sigma}^{\prime}-x_{q \Sigma}}{x_{d \Sigma}^{\prime} X_{q \Sigma}} \sin 2\left[\sum_{i=0}^{4} \delta_{(i)}(t) U_{i}(u)\right]\right) p(u) d u
\end{aligned}
$$

Finally, the average response can be evaluated according to the Eq. (11): 


$$
\left\{\begin{array}{l}
E\left[x_{1}(t, u)\right]=\sum_{i=0}^{4} x_{1(i)}(t) U_{i}(u)=x_{10}(t) \\
E\left[x_{2}(t, u)\right]=\sum_{i=0}^{4} x_{2(i)}(t) U_{i}(u)=x_{20}(t) \\
E\left[x_{3}(t, u)\right]=\sum_{i=0}^{4} x_{3(i)}(t) U_{i}(u)=x_{30}(t) \\
E[\delta(t, u)]=\sum_{i=0}^{4} \delta_{(i)}(t) U_{i}(u)=\delta_{0}(t) \\
E[\omega(t, u)]=\sum_{i=0}^{4} \omega_{(i)}(t) U_{i}(u)=\omega_{0}(t) \\
E[y(t, u)]=\sum_{i=0}^{4} y_{(i)}(t) U_{i}(u)=y_{0}(t) \\
E\left[x_{4 i}(t, u)\right]=\sum_{i=0}^{4} x_{4 i}(t) U_{i}(u)=x_{40}(t)
\end{array}\right.
$$

\subsection{Sensitivity method}

Sensitivity analysis is used to quantize the effect of the parametric uncertainties on the system output [40]. The sensitivity indices include two parts, namely the main effect (i.e., the effect of single uncertain parameter on the system output) and the total effect (i.e., the interaction effect of multi-uncertain parameters on the system output). Its algorithm is briefly described as follows.

First, select an appropriate search function $G_{i}$. Using this function $G_{i}$, the system model $Y=f\left(x_{1}, x_{2}, \ldots, x_{n}\right)$ is transformed into a novel function expressed as $Y=f(s)$. The relationship between the search function $G_{i}$ and the input parameter $x_{i}$ is

$$
x_{i}(s)=G_{i}\left[\sin \left(\omega_{i} s\right)\right]
$$

where $n$ is the number of the input uncertain parameters, $i \in(1, n) ;\{\omega\}$ is defined as the frequency of the integer. In addition, the function $G_{i}$ should meet the following condition:

$$
\pi\left(1-x_{i}^{2}\right)^{0.5} P_{i} G_{i} \frac{d G_{i}\left(x_{i}\right)}{d x_{i}}=1
$$

where $P_{i}$ is the probability density function of the uncertain parameter $x_{i}$. Next, we integrate $x_{i}$ to Eq. (15) and calculate its Fourier transform, obtained as:

$$
y=f(s)=\sum_{j=-\infty}^{j=+\infty} A_{j} \cos (j s)+B_{j} \sin (j s)
$$

where

$$
j \in\left\{-\frac{N_{s}-1}{2}, \ldots,-1,0,1, \ldots,+\frac{N_{s}-1}{2}\right\}, A_{j}=\frac{1}{2 \pi} \int_{\pi}^{\pi} f(s) \cos (j s) d s, B_{j}=\frac{1}{2 \pi} \int_{\pi}^{\pi} f(s) \sin (j s) d s,
$$

$N_{s}$ is the sampling number. Thus, Fourier series spectrum curve is defined as:

$$
\Lambda_{j}=A_{j}^{2}+B_{j}^{2}
$$


The variance of model output caused by the uncertain parameter $x_{i}$ is expressed as:

$$
V_{i}=2 \sum_{i=1}^{+\infty} \Lambda_{i} \omega_{i}
$$

Based on Eq. (18), the total variance of the model output is written as:

$$
V=\sum_{i} V_{i}+\sum_{i \neq j} V_{i j}+\sum_{i \neq j \neq k} V_{i j k}+\ldots+\sum_{i} V_{12 \cdots n}
$$

where $V_{i j}$ is the variance of parameter $x_{i}$ affected by $x_{j}$; $V_{i j m}$ is the variance of parameter $x_{i}$ affected by the coupling of $x_{j}$ and $x_{m}$. $V_{12 \ldots \mathrm{n}}$ is variance of parameter $x_{i}$ affected by the coupling of $x_{1}, x_{2}, x_{3}, \ldots$, and $x_{n}$. Normalize model parameters and the main effect $S_{i}$ is expressed as:

$$
S_{i}=\frac{V_{i}}{V}
$$

The total effect of parameter $x_{i}$ is

$$
S_{T i}=\frac{V-V_{-i}}{V}
$$

where $V_{-i}$ does not include the sum of variance regarding $x_{i}$.

\section{Numerical simulations}

The proposed model was applied to a case-study in order to prove the efficiency and consistency of this approach. The values adopted for the parameters involved in the computations are shown in Tab. 1.

The initial values of the deterministic model of the hydraulic-mechanical-electric system (1) are

$\left[x_{1}(0), x_{2}(0), x_{3}(0), \delta(0), \omega(0), y(0), x_{4}(0)\right]=[0.001,0.001,0.001,0.001,0.001$, $0.001,0.001]$.

The initial values of the random hydraulic-mechanical-electric system (11) are $\left[x_{10}(0), x_{20}(0), x_{30}(0), \delta_{0}(0), \omega_{0}(0), y_{0}(0), x_{40}(0)\right]=[0.001,0.001,0.001,0.001,0.001$, $0.001,0.001]$, and $\left[x_{1 i}(0), x_{2 i}(0), x_{3 i}(0), \delta_{i}(0), \omega_{i}(0), y_{i}(0), x_{4 i}(0)\right]=[0,0,0,0,0,0,0]$ $(i=0,1,2,3,4)$.

The polynomial approximation method is proposed by Jensen et al. Xu et al [39] especially developed this method in his book and pointed out that the responses show a good precision when $N$ is large than or equal to 4.To verify the simulation precision, we performed a comparison of the response of generator speed with different value of N, as shown in Fig. 3. 

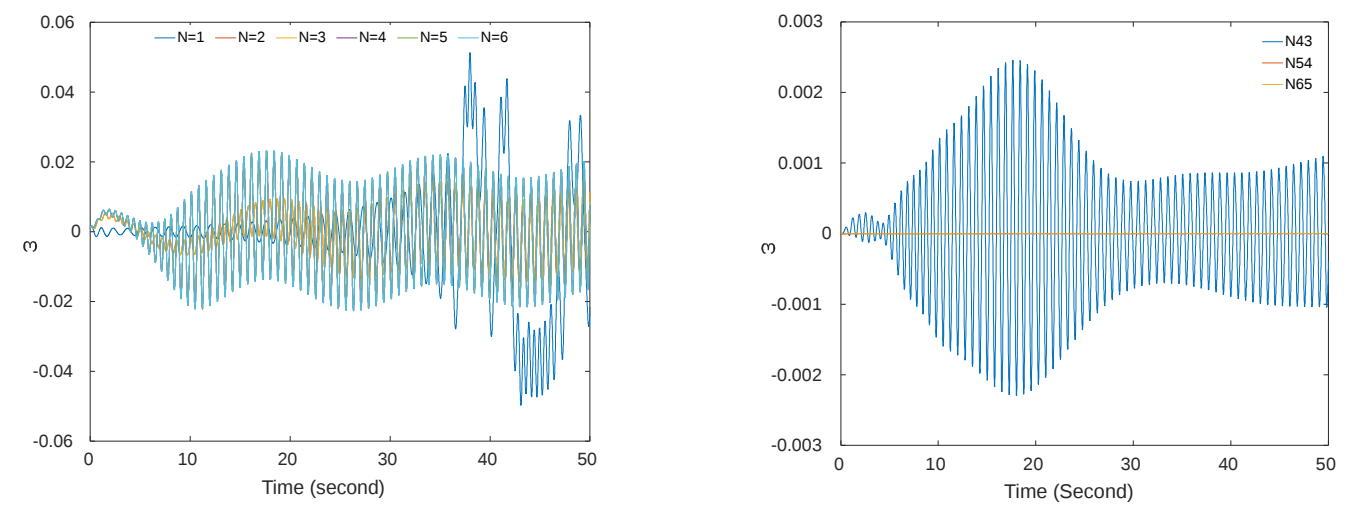

(a) Responses of the generator speed with different values of N. (b) Difference of the responses of generator speed.

Fig. 3 Responses of generator speed with different values of $\mathrm{N}$ and the difference between two different responses. (a) Responses of the generator speed with different values of $N$. (b) Difference of the responses of the generator speed. $N$ is the maximum number of the Chebyshev polynomials. Different value of $\mathrm{N}$ means the different simulation result of the generator speed transformed by number $N$ of Chebyshev polynomial. $N 43$ denotes the difference between the speed responses with the maxmum Chebyshev polynomial $N=4$ and $N=3$; $N 54$ denotes the difference between the speed responses with the maxmum Chebyshev polynomial $N=5$ and $N=4 ; N 65$ is the difference between the speed responses with the maxmum Chebyshev polynomial $N=6$ and $N=5$. Model parameters are assigned to average values coming from Tab. 1.

As shown in Fig. 3(a), the dynamic evaluations of the generator speed are clearly different when $N<4$. While $N>4$, the dynamic evaluations of speed with different value of $\mathrm{N}$ are basically overlapped. From Fig. 3(b), the order of magnitude regarding $N 54$ and $N 65$, at least, is $10^{-4}$, meaning that the error of the speed response is less than $1 \%$ when $N>4$. This error indicates that the Chebyshev polynomial fitting method can capture the dynamic characteristics of the hydraulic-mechanical-electric system accurately and quickly.

\subsection{Global Sensitivity analysis}

Global sensitivity aims to find sensitive factors defined as parameters which have important effect on system outputs. In this subsection, global sensitivity to the generator speed is performed, and the calculation result is shown in Fig. 4. Parametric uncertainties in the established model are shown in Tab. 1. There are three main differences compared to the public design approaches with the provided method in this manuscript. First, most public models come from the Ref. [15] proposed by the IEEE Group. These models are differential equations. The model in this manuscript is also developed based on the IEEE Group's model by introducing a random excitation. It is therefore a model of stochastic differential 
equations. Second, from the viewpoint of engineering, the excitation from the electric power system is essentially random. Hence, the model introducing a random excitation would be more reasonable than public models considering the excitation as a constant value. Third, the public models can be simulated by many numerical methods, such as Runge-Kutta method and Admas-Bashforth-Moulton algorithm. These methods, however, cannot be used to simulate the random model due to the random excitation. Chebyshev polynomial approximation method is specially adapted to approximate the random excitation. Table 2 is added to detail the main differences between public design approaches and the newly provided method.

Table 1 Definition of parametric uncertainties. The definition of uncertain parameters is used to investigate its effect on system outputs. All the parameters obey the normal distribution. Average and standard values are defined based on engineering experience.

\begin{tabular}{llllll}
\hline Definition & Symbol & Average & Standard & Distribution \\
\hline Partial derivative of the flow with turbine speed & $e_{q h}$ & 0.5 & 0.01 & Normal \\
Partial derivative of turbine torque with guide & $e_{y}$ & 0.03 & 0.01 & Normal \\
vane & & & & \\
Partial derivative of the flow with guide vane & $e_{q y}$ & 0.2 & 0.01 & Normal \\
Partial derivative of torque with turbine speed & $e_{h}$ & 0.18 & 0.01 & Normal \\
Damping factor of generator rotor & $D_{t}$ & 0.5 & 0.01 & Normal \\
Transient internal voltage of the armature & $E_{q}$ & 1.35 & 0.1 & Normal \\
the rated generator speed & $\omega_{0}$ & 314 & 100 & Normal \\
Inertia time constant of the generator unit & $T_{a b}$ & 8 & 0.5 & Normal \\
Direct axis transient reactance & $x_{d}$ & 1.15 & 0.01 & Normal \\
Quadrature axis reactance & $x_{q}$ & 1.474 & 0.01 & Normal \\
Major relay connecter response time & $T_{y}$ & 0.1 & 0.001 & Normal \\
Bus voltage at infinity & $V_{s}$ & 1 & 0.01 & Normal \\
Length of the phase of water hammer wave & $T_{r}$ & 1 & 0.01 & Normal \\
Elastic time constant of the penstock & $h_{w}$ & 2 & 0.01 & Normal \\
Proportional adjustment coefficient & $k_{p}$ & 2 & 0.01 & Normal \\
Integral adjustment coefficient & $k_{i}$ & 1 & 0.01 & Normal \\
Differential adjustment coefficient & $k_{d}$ & 2 & 0.06 & Normal \\
Random intensity & $D$ & 0.08 & 0.0003 & Normal \\
Control signal & $r$ & 0.01 & 0.003 & Normal \\
\hline
\end{tabular}

Table 2 Main difference between public design approaches and the newly provided method. 


\begin{tabular}{|c|c|c|}
\hline Model Type & $\begin{array}{l}\text { Deterministic differential } \\
\text { equations }\end{array}$ & Stochastic differential equations \\
\hline Numerical method & Runge-Kutta method & $\begin{array}{l}\text { Chebyshev polynomial approximation } \\
\text { + Runge-Kutta method }\end{array}$ \\
\hline
\end{tabular}

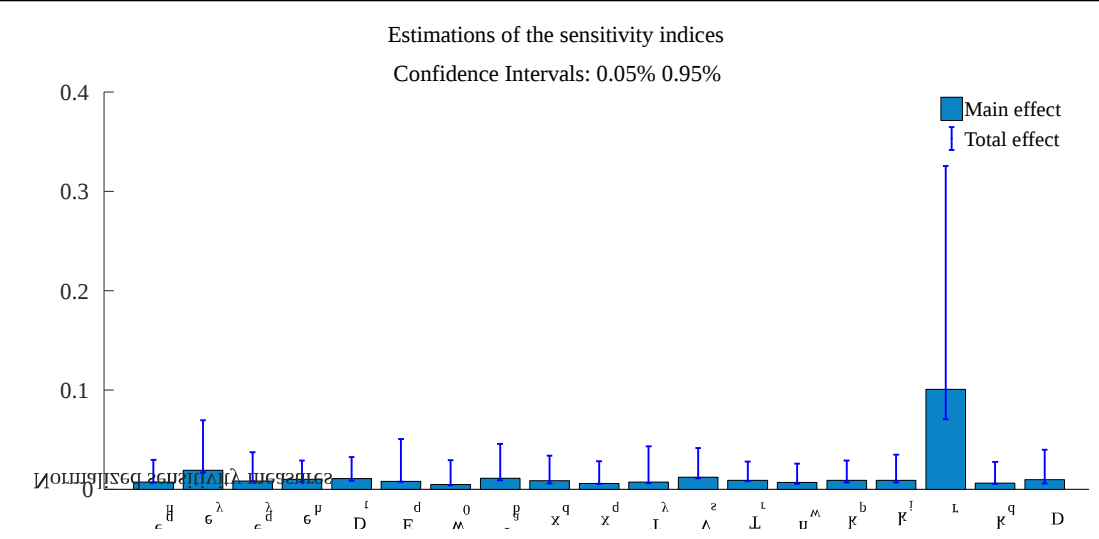

Fig. 4 Sensitivity indices regarding the generator speed versus system parameters. The blue box plots show the main effect of the parameters on the generator speed. The error bars on the boxes indicate the uncertainties of parameters. The confidence interval is $(0.05 \%, 0.95 \%)$. Simulations were performed using the average values of all the uncertain parameters (Table 1). The calculation method is the Extended Fourier Amplitude Sensitivity Test. It shows that the control signal r plays the major contribution to the value of generator speed.

From Fig. 4, the sensitive indice of the control signal $r$ is obviously larger than that of other parameters for the generator speed. In actual operating, the control signal $r$ provides a standard for the generator speed, and the aim of the system is to regulate the guide vane opening to guarantee the generator speed changing in the required interval. Hence, it is very reasonable that the control signal $r$ plays the most sensitive parameter. The impact degree of parameters on the generator speed are ranged, namely $r>V_{s}>T_{a b}>D_{t}>e_{h}>D>k_{i}>T_{r}>k_{p}>x_{d}>e_{q y}>E_{q}>T_{y}>e_{q h}$ $>h_{w}>k_{d}>x_{q}>w_{0}>e_{y}$.

\subsection{Dynamic evolution with different levels of random intensity $D$}

In this subsection, the differences between the dynamic evolution process of the generator speed $\omega$ computed with the deterministic (1) and a probabilistic approach (11) are investigated. Let the differential gain of the PID controller $k_{d}$ vary between 0 and 6 . The dynamic evolution process of the generator speed $\omega$ is obtained adopting the deterministic approach of Eq. (1): the results of such analysis are shown in Fig. 5(a). Similarly, Fig. 5(b) shows the results adopting the probabilistic approach of Eq. (11) with regard to the generator speed. The dynamic evolution process of the generator speed $\omega$ along with increasing differential gain values $k_{d}$, assuming a random intensity D equal to 0.01 . 


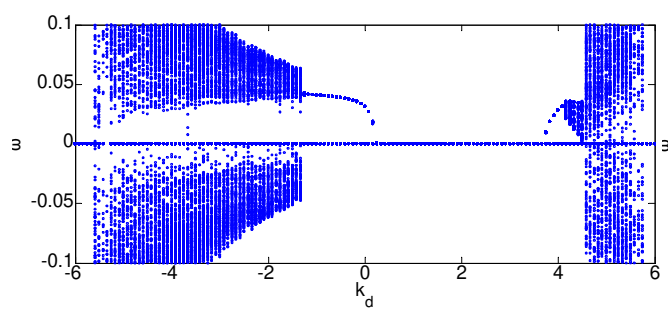

(a) Responses of the deterministic system (1)

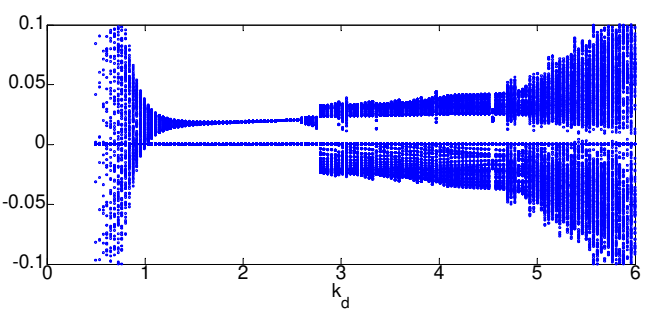

(b) $D=0.01$

Fig. 5 The dynamic evolution of the generator speed $\omega$ for the traditional model of Eq. (1) and the probabilistic model of Eq. (11), with $D=0.01$ and differential gain $k_{d}$ increasing from 0 to 6 . Blue dot in the plots is the output value of the generator speed regarding different value of $k_{d}$, and only a value of $k_{d}$ regarding a definite value of the generator speed means the stable operation. Simulations were performed using the average values of all the uncertain parameters (Table 1). This figure mainly shows that the random excitation $u$ narrows the adjustable range of $k_{d}$ associated with the random vibration state, indicating that the random excitation in modeling the system should be considered.

As Fig. 5(a), for $k_{d}$ varying between 0 and 6, the results of the deterministic approach highlight five operating states associated with the dynamic evolution process of the generator speed $\omega$ : a random vibration state for the generator speed $\omega$ within the range $[-0.1,0.1]$, a regular vibration state from $\omega=0.0188$ to $\omega$ $=0.02015$, a stable operation state when $\omega$ is equal to zero, a quasi-periodic vibration state for values of $\omega$ lying in the interval [-0.037, 0.042], and a nontunable state for values of $\omega$ far higher than zero. In comparison with Fig. 5(a), Fig. 5(b) shows a different dynamic evolution process of the generator speed $\omega$ when $k_{d}$ changes from 0 to 6 . Specifically, the difference between the two approaches can be summarized by five observations:

First, for the deterministic approach of Eq. (1), the key point (named point 1) at which the generator speed $\omega$ evolves from the non-tunable state to the random vibration state is located at $k_{d}=-5.583$. Differently, point 1 is located at $k_{d}=0.5$ for the probabilistic approach of Eq. (11).

Second, the critical point (named point 2) at which $\omega$ passes from the random vibration state to the stable operating state, moves from $k_{d}=-1.25$ to $k_{d}=1.875$ according to the adoption of the deterministic or the probabilistic approach respectively. The distance between point 1 and point 2 reveals that the adjustable range of $k_{d}$ associated with the random vibration state is significantly tighter for the probabilistic case. In other words, minor changes of the value of $k_{d}$ may result in the transition of the probabilistic model from the random vibration state to the 
non-tunable state. This transition could result in major accidents and then could have disastrous effects on the facility and its surroundings. Third, the deterministic model presents a stable state, and the corresponding adjustable range of $k_{d}$ is [0.1667, 3.75]. Differently, the probabilistic model presents no stable state. Fourth, considering the deterministic model operating in the regular vibration state, the change rate of the generator speed is very large, while the change rate becomes quite low when the random system operates in the regular vibration state.

Fifth, with regard to the quasi periodic vibration state, the range of $k_{d}$ results [4.167, 4.5] for the deterministic model and [2.563, 4.663] for the probabilistic approach.

To sum up, the results obtained with the probabilistic model do not show any stable operating state of the hydraulic-mechanical-electric system affected by the random fluctuation of the generator speed. Moreover, in comparison with the deterministic analysis, the adjustable range of $k_{d}$ associated with the random vibration state is narrower, while it appears significantly wider in the right region of the domain, associated with the quasi periodic vibration state.

\subsection{Definition of $k_{d}$ in function of random intensity $D$}

This section is dedicated to the study of the effects of the intensity $D$ on the adjustable range of the differential gain $k_{d}$. Furthermore, the relation between this latter and increasing value of $D$ is established mathematically. Fig. 6 shows the dynamic evolution of the generator speed computed with the probabilistic model of Eq.(11) for different levels of the intensity $D$ and values of $k_{d}$ within the range $[0,6]$.

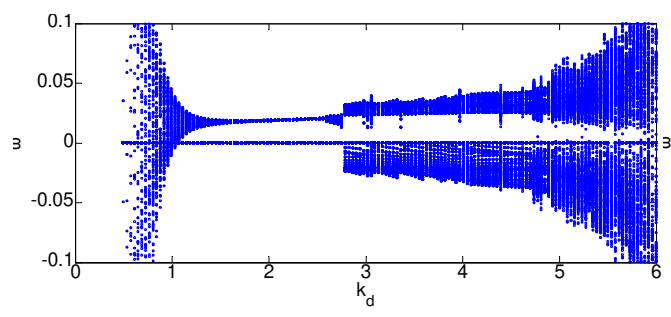

(a) $D=0.06$

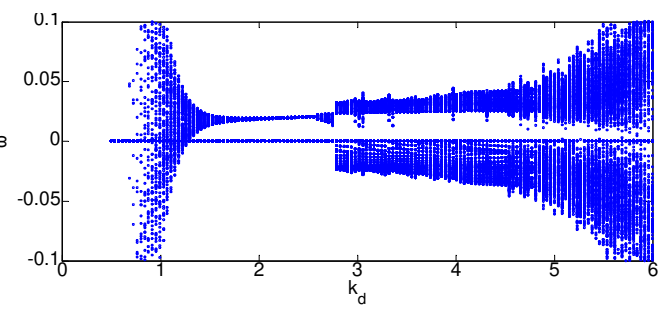

(b) $D=0.18$ 


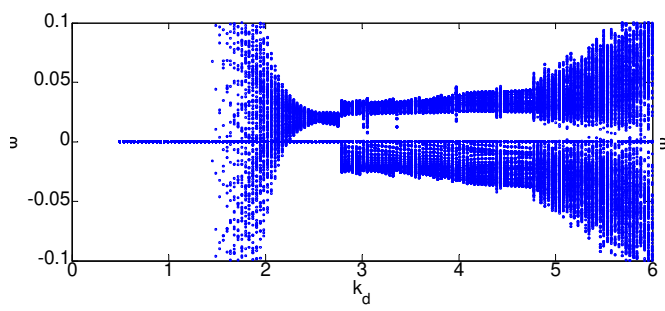

(c) $D=0.54$

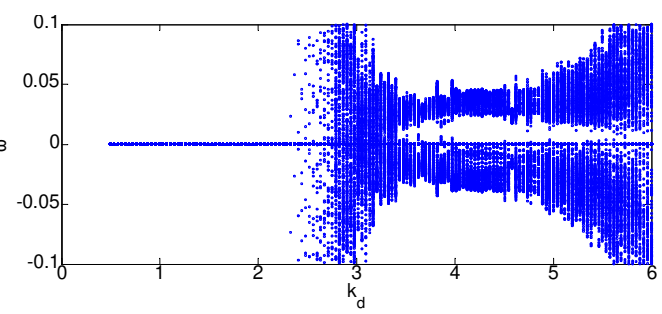

(d) $D=0.88$

Fig. 6 Dynamic evolution of the generator speed $\omega$ for the probabilistic model of Eq. (11) with different levels of intensity $D$ and $k_{d}$ varying from 0 to 6. (a) $D=0.06$; (b) $D=0.18$; (c) $D=0.54$; (d) $D=0.88$; Blue dot in the plots is the output value of generator speed regarding different value of $k_{d}$, and a value of $k_{d}$ regarding uncertain values of generator speed may cause load rejection failure. Simulations were performed using the average values of all the uncertain parameters (Table 1). This figure mainly investigates how the adjustable range of variable $k_{d}$ changes with the increasing level of intensity $D$.

The results show that, with increasing level of the intensity $D$, the range of $k_{d}$ which corresponds to the random vibration state on the left of point 2, does not change, as well as the operating state of the hydro-turbine generator system on the right of point 2. Conversely, the region of the $k_{d}$ domain corresponding to the random vibration state and the non-tunable state shifts progressively to the right along with the increase of the intensity $D$. This implies that the range of $k_{d}$ corresponding to the regular vibration state decreases gradually with the growth of $D$. When the value of $D$ increases to 0.40 , the point 2 coincides with the key point for which the system evolves from the regular vibration state to the quasi periodic vibration state. Note that, under these conditions, the range of the quasi periodic vibration state expands suddenly and the system evolves progressively from the non-tunable state to the random vibration state and hence to the quasi periodic vibration state along the $k_{d}$ domain. Under these circumstances, the severity of the system vibrations cannot be significantly decreased, regardless the entity of the adjustment applied to the value of $k_{d}$. Further, increasing the intensity $D$, the system shows only two possible states: the random vibrations state and the nontunable state. Tab. 3 presents the state of the system for different values of the intensity $D$ and different ranges of $k_{d}$.

Table 3 Change laws of point 2 and operating ranges with increasing level of the random intensity $D$. This table reveals how the adjustable range of $k_{d}$ decreases with the increasing level of the intensity $D$.

$\mathrm{D} \quad k_{d}$ 


\begin{tabular}{|c|c|c|c|c|c|c|}
\hline & State & Range & State & Range & State & range \\
\hline 0.01 & $\begin{array}{l}\text { Random } \\
\text { vibration }\end{array}$ & $\begin{array}{l}(0.4236 \\
0.8056)\end{array}$ & $\begin{array}{l}\text { Regular } \\
\text { vibration }\end{array}$ & $\begin{array}{l}(\mathbf{1}, \mathbf{8 7 5} \\
2.563)\end{array}$ & $\begin{array}{l}\text { Quasi } \\
\text { periodic } \\
\text { vibration }\end{array}$ & $\begin{array}{l}(2.563 \\
4.663)\end{array}$ \\
\hline 0.06 & $\begin{array}{l}\text { Random } \\
\text { vibration }\end{array}$ & $\begin{array}{l}(0.4999 \\
0.8819)\end{array}$ & $\begin{array}{l}\text { Regular } \\
\text { vibration }\end{array}$ & $\begin{array}{l}\text { (1.951, } \\
2.563)\end{array}$ & $\begin{array}{l}\text { Quasi } \\
\text { periodic } \\
\text { vibration }\end{array}$ & $\begin{array}{l}(2.563 \\
4.663)\end{array}$ \\
\hline 0.12 & $\begin{array}{l}\text { Random } \\
\text { vibration }\end{array}$ & $\begin{array}{l}(0.5763 \\
0.9583)\end{array}$ & $\begin{array}{l}\text { Regular } \\
\text { vibration }\end{array}$ & $\begin{array}{l}(\mathbf{2 . 0 2 8} \\
2.563)\end{array}$ & $\begin{array}{l}\text { Quasi } \\
\text { periodic } \\
\text { vibration }\end{array}$ & $\begin{array}{l}(2.563 \\
4.663)\end{array}$ \\
\hline 0.18 & $\begin{array}{l}\text { Random } \\
\text { vibration }\end{array}$ & $\begin{array}{l}\text { (0.691, } \\
1.073)\end{array}$ & $\begin{array}{l}\text { Regular } \\
\text { vibration }\end{array}$ & $\begin{array}{l}(2.181 \\
2.563)\end{array}$ & $\begin{array}{l}\text { Quasi } \\
\text { periodic } \\
\text { vibration }\end{array}$ & $\begin{array}{l}(2.563 \\
4.663)\end{array}$ \\
\hline 0.24 & $\begin{array}{l}\text { Random } \\
\text { vibration }\end{array}$ & $\begin{array}{l}(0.806 \\
1.188)\end{array}$ & $\begin{array}{l}\text { Regular } \\
\text { vibration }\end{array}$ & $\begin{array}{l}\text { (2.257, } \\
2.563)\end{array}$ & $\begin{array}{l}\text { Quasi } \\
\text { periodic } \\
\text { vibration }\end{array}$ & $\begin{array}{l}(2.563 \\
4.663)\end{array}$ \\
\hline 0.30 & $\begin{array}{l}\text { Random } \\
\text { vibration }\end{array}$ & $\begin{array}{l}(0.958, \\
1.340)\end{array}$ & $\begin{array}{l}\text { Regular } \\
\text { vibration }\end{array}$ & $\begin{array}{l}(2.333,2.563 \\
)\end{array}$ & $\begin{array}{l}\text { Quasi } \\
\text { periodic } \\
\text { vibration }\end{array}$ & $\begin{array}{l}(2.563 \\
4.663)\end{array}$ \\
\hline 0.36 & $\begin{array}{l}\text { Random } \\
\text { vibration }\end{array}$ & $\begin{array}{l}(1.111, \\
1.493)\end{array}$ & $\begin{array}{l}\text { Regular } \\
\text { vibration }\end{array}$ & $\begin{array}{l}(\mathbf{2 . 4 6 6} \\
2.563)\end{array}$ & $\begin{array}{l}\text { Quasi } \\
\text { periodic } \\
\text { vibration }\end{array}$ & $\begin{array}{l}(2.563 \\
4.663)\end{array}$ \\
\hline 0.42 & $\begin{array}{l}\text { Random } \\
\text { vibration }\end{array}$ & $\begin{array}{l}(1.264, \\
1.646)\end{array}$ & $\begin{array}{l}\text { Regular } \\
\text { vibration }\end{array}$ & & $\begin{array}{l}\text { Quasi } \\
\text { periodic } \\
\text { vibration }\end{array}$ & $\begin{array}{l}(1.646, \\
4.663)\end{array}$ \\
\hline 0.48 & $\begin{array}{l}\text { Random } \\
\text { vibration }\end{array}$ & $\begin{array}{l}\text { (1.455, } \\
1.837)\end{array}$ & $\begin{array}{l}\text { Regular } \\
\text { vibration }\end{array}$ & & $\begin{array}{l}\text { Quasi } \\
\text { periodic } \\
\text { vibration }\end{array}$ & $\begin{array}{l}\text { (1.837, } \\
4.663)\end{array}$ \\
\hline 0.54 & $\begin{array}{l}\text { Random } \\
\text { vibration }\end{array}$ & $\begin{array}{l}\text { (1.646, } \\
2.028)\end{array}$ & $\begin{array}{l}\text { Regular } \\
\text { vibration }\end{array}$ & & $\begin{array}{l}\text { Quasi } \\
\text { periodic } \\
\text { vibration }\end{array}$ & $\begin{array}{l}(2.028,4.663 \\
)\end{array}$ \\
\hline 0.60 & $\begin{array}{l}\text { Random } \\
\text { vibration }\end{array}$ & $\begin{array}{l}\text { (1.799, } \\
2.181)\end{array}$ & $\begin{array}{l}\text { Regular } \\
\text { vibration }\end{array}$ & & $\begin{array}{l}\text { Quasi } \\
\text { periodic } \\
\text { vibration }\end{array}$ & $\begin{array}{l}(2.181, \\
4.663)\end{array}$ \\
\hline 0.72 & $\begin{array}{l}\text { Random } \\
\text { vibration }\end{array}$ & $\begin{array}{l}(2.142, \\
2.524)\end{array}$ & $\begin{array}{l}\text { Regular } \\
\text { vibration }\end{array}$ & & $\begin{array}{l}\text { Quasi } \\
\text { periodic } \\
\text { vibration }\end{array}$ & $\begin{array}{l}(2.524, \\
4.633)\end{array}$ \\
\hline 0.88 & $\begin{array}{l}\text { Random } \\
\text { vibration }\end{array}$ & $\begin{array}{l}(2.792, \\
3.174)\end{array}$ & $\begin{array}{l}\text { Regular } \\
\text { vibration }\end{array}$ & & $\begin{array}{l}\text { Quasi } \\
\text { periodic } \\
\text { vibration }\end{array}$ & $\begin{array}{l}(3.174, \\
4.633)\end{array}$ \\
\hline
\end{tabular}


The results of the analysis carried out show that the intensity $D$ affects only the value of point 2. Moreover, this latter shifts to the right with increasing level of the intensity $D$, and for this reason the intensity $\mathrm{D}$ seems to have an impact on the stability of the system.

\subsection{Comparison of the grid water hammer and the elastic water hammer models}

Technically, the penstock wall of hydropower stations is elastic. As far as the length of the penstock is less than $600 \mathrm{~m}$, its shape change almost has no effect on water hammer. Thus, grid water hammer models are widely used in modeling the dynamic characteristics of small and medium hydropower stations. In this section, a comparison of the operating range between the grid water hammer and the elastic water hammer models is proposed.

Substituting the grid water hammer model with the elastic water hammer model in Eq. (1), then the hydraulic-mechanical-electric system can be rewritten as:

$$
\left\{\begin{array}{l}
\dot{\delta}=\omega_{s} \omega \\
\dot{\omega}=\frac{1}{T_{a b}}\left(m_{t}-\frac{E_{q}^{\prime} V_{s}}{x_{d \Sigma}^{\prime}} \sin \delta-\frac{V_{s}^{2}}{2} \frac{x_{d \Sigma}^{\prime}-x_{q \Sigma}}{x_{d \Sigma}^{\prime} x_{q \Sigma}} \sin 2 \delta-D_{t} \omega-D u \omega\right) \\
\dot{m}_{t}=\frac{1}{e_{q h} T_{w}}\left[-m_{t}+e_{y} y-\frac{e e_{y} T_{w}}{T_{y}}\left(k_{p}(r-\omega)+k_{i} x_{4}-k_{d} \dot{\omega}-y\right)\right] \\
\dot{y}=\frac{1}{T_{y}}\left(k_{p}(r-\omega)+k_{i} x_{4}-k_{d} \dot{\omega}-y\right) \\
\dot{x}_{4}=r-\omega
\end{array}\right.
$$

The trend associated with a point named 3, namely the value of $k_{d}$ for which the generator speed $\omega$ passes from the non-tunable to the vibration state, is shown in Tab. 4.
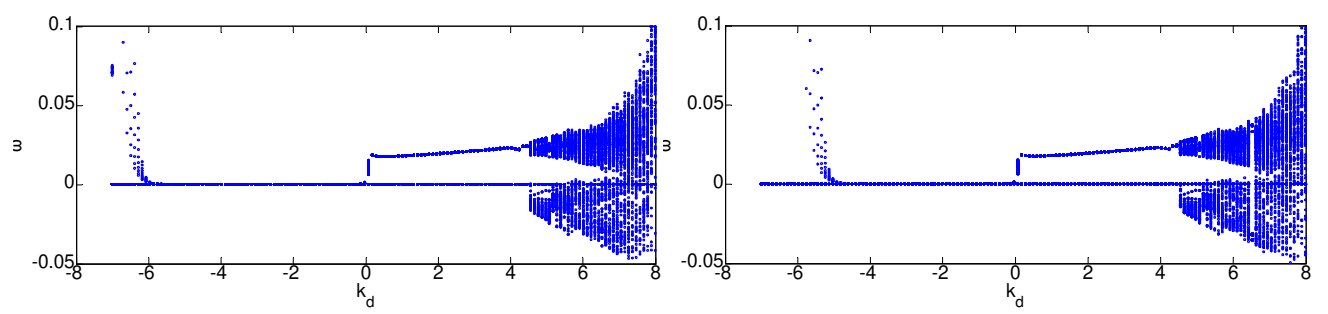
(a) $\mathrm{D}=0.06$
(b) $\mathrm{D}=0.16$ 

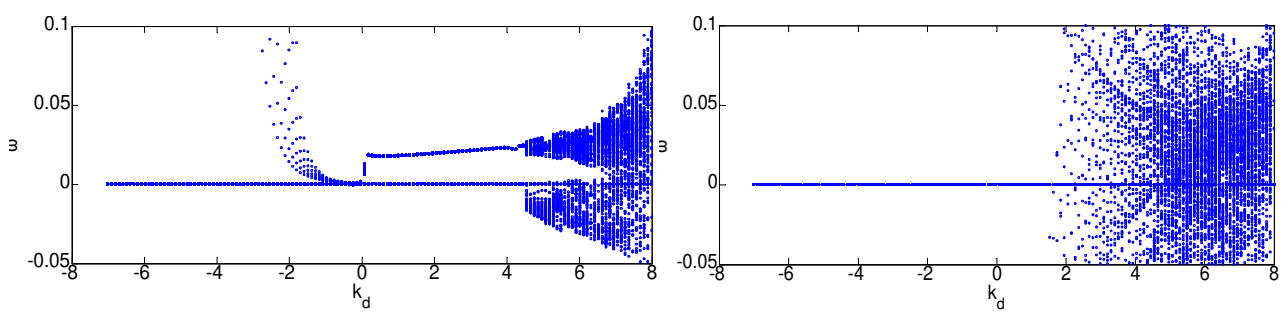

(c) $\mathrm{D}=0.36$

(d) $\mathrm{D}=0.52$

Fig. 7 Dynamic evolution of the generator speed $\omega$ for the probabilistic model in Eq. (15) with different values of the random intensity $D$ and $k_{d}$ varying from -8 to 8 . (a) $D=0.06$; (b) $D=0.16$; (c) $D=0.36$; $(d) D=0.52$; Blue dot in the plots is the output value of the generator speed regarding different value of $k_{d}$, and a value of $k_{d}$ regarding uncertain values of the generator speed may cause load rejection failure. Simulations were performed using the average values of all the uncertain parameters (Table 1). This figure mainly shows how the adjustable range of the variable $k_{d}$ changes with the increasing level of intensity $D$.

Table 4 Location of point 3 according to increasing values of the random intensity $D$. This table illustrates that the trend registered for the probabilistic model in Eq. (15) matches perfectly the results obtained from the previous probabilistic model of Eq. (11).

\begin{tabular}{llllllllllll}
\hline$D$ & 0.04 & 0.06 & 0.08 & 0.12 & 0.16 & 0.20 & 0.24 & 0.28 & 0.32 & 0.36 & 0.40 \\
\hline \multirow{2}{*}{ Point3 } & -5.854 & - & - & - & - & - & -3.25 & - & - & - & 0.083 \\
& & 5.646 & 5.542 & 5.021 & 4.604 & 3.979 & & 2.521 & 1.479 & 0.2292 & \\
\hline
\end{tabular}

As shown in Tab. 4, increasing levels of the intensity $D$ cause the region of the domain associated with the non-tunable state shifting to the right, while the operating state on the right of point 3 remains unchanged. As expected, the trend registered for the probabilistic model in Eq. (15), considering the rigid water hammer model, matches perfectly the results obtained for the previous probabilistic model of Eq. (11).

\section{Conclusions}

In this study, a random variable $u$ is integrated with the generator speed of the deterministic model of a hydraulic-mechanical-electric system to establish the corresponding probabilistic model. Using this latter, the dynamic evolution of the system is analyzed, and three main conclusions are achieved. First, although the dynamic evolution of the random system is broadly similar to that of the deterministic approach, the two sets of results show significant differences, carefully investigated in the paper. Second, the point 3, which highlights the transition from the not-tunable state to the random vibration state, shifts to the right with increasing values of the random intensity $D$, which leads to the 
decreasing adjustable range of $k_{d}$. Third, the consistence of the trends highlighted by the probabilistic model implemented in this paper is compared and verified through the use of another model. Moreover, when the shape of the penstock is assumed not uniform, the adjustable range of $k_{d}$ is narrowed from left to right and the operating state of the system becomes less stable. In light of the obtained results and of the rapid development of wind power, it is recommendable to select values of the differential gain $k_{d}$ of the PID governor as large as possible.

\section{Acknowledgment}

This work was supported by the scientific research foundation of National Natural Science Foundation--Outstanding Youth Foundation (51622906), National Natural Science Foundation (51479173), Fundamental Research Funds for the Central Universities (201304030577), Scientific research funds of Northwest A\&F University (2013BSJJ095), Science Fund for Excellent Young Scholars from Northwest A\&F University and Shaanxi Nova program (2016KJXX-55).

\section{References}

[1] Qin, C., Innes-Wimsatt, E., Loth, E. Hydraulic-electric hybrid wind turbines: Tower mass saving and energy storage capacity. Renew. Energ. 99, 69-79 (2016).

[2] Chu, S., Majumdar, A. Opportunities and challenges for a sustainable energy future. Nature 488(7411), 294 (2012).

[3] Amirante, R., Cassone, E., Distaso, E., Tamburrano, P. Overview on recent developments in energy storage: Mechanical, electrochemical and hydrogen technologies. Energ. Convers. Manage. 132, 372-87 (2017).

[4] Simeons, C. Hydro-Power-The use of water as an alternative source of energy. Pergamen Press, 1980.

[5] Shan, B.G., Tan, X.D., Wen, Q., Han X.Y. Analysis and prediction of China’s electricity demand and supply in 2013. Electric Power 46(8), 7-10 (2013).

[6] Balkhair, K.S., Rahman, K.U. Sustainable and economical small-scale and low-head hydropower generation: A promising alternative potential solution for energy generation at local and regional scale. Appl. Energ. 188, 378-391 (2017).

[7] Qian, J., Zeng, Y., Guo, Y.K., Zhang, L.X. Reconstruction of the complete characteristics of the hydro turbine based on inner energy loss. Nonlinear Dynam. 86(2), 963-974 (2016).

[8] Luongo, A., Zulli, D. Nonlinear energy sink to control elastic strings: the internal resonance case. Nonlinear Dynam. 81(1-2), 425-435 (2015).

[9] Mesnage, H., Alamir, M., Perrissin-Fabert, N., et al. Nonlinear model-based control for minimum-time start of hydraulic turbines. Eur. J. Control 34, 24-30 (2017).

[10] Hydraulic Turbine Regulating System With Uncertainties Using Three Different Approaches. IEEE T. Power Syst. 32(5), 3482-3491 (2017). 
[11] Xu, B.B., Chen, D.Y., Zhang, H., Zhou, R. Dynamic analysis and modeling of a novel fractional-order hydro-turbine-generator unit. Nonlinear Dynam. 81(3), 1263-1274 (2015). [12] Liu, X., Liu, C. Eigenanalysis of Oscillatory Instability of a Hydropower Plant Including Water Conduit Dynamics. IEEE T. Power Syst. 22(2), 675-681 (2007).

[13] Bergant, A., Simpson, A.R., Tijsseling, A.S. Water hammer with column separation: A historical review. J. Fluid. Struct. 22(2), 135-171 (2006).

[14] Kavurmaci, B., Celebioglu, K., Aradag, S., et al. Model Testing of Francis-Type Hydraulic Turbines. Meas. Control-UK 50(3), 70-73 (2017).

[15] Group, W.. Hydraulic turbine and turbine control models for system dynamic studies. IEEE T. Power Syst. 7(1), 167-179 (1992).

[16] Baloch, M.H., Wang, J., Kaloi, G.S. Stability and nonlinear controller analysis of wind energy conversion system with random wind speed. Int. J. Elec. Power 79, 75-83 (2016).

[17] Kaloi, G.S., Wang, J., Baloch, M.H. Dynamic Modeling and Control of DFIG for Wind Energy Conversion System Using Feedback Linearization. J. Electr. Eng. Technol. 11(5), 11371146 (2016).

[18] Xu, B., Wang, F., Chen, D.Y., Zhang, H. Hamiltonian modeling of multi-hydro-turbine governing systems with sharing common penstock and dynamic analyses under shock load. Energ. Convers. Manage. 108, 478-487 (2016).

[19] Afshar, M.H., Rohani, M., Taheri, R. Simulation of transient flow in pipeline systems due to load rejection and load acceptance by hydroelectric power plants. Int. J. Mech. Sci. 52(1), 103-115 (2010).

[20] Chen, J., Yang, H.X., Liu, C.P., Lau, C.H., Lo, M. A novel vertical axis water turbine for power generation from water pipelines. Energy 54(2), 184-193 (2013).

[21] Zhang, H., Chen, D., Xu, B., Wu, C.Z., Wang, X.Y. The slow-fast dynamical behaviors of a hydro-turbine governing system under periodic excitations. Nonlinear Dynam. 87(4), 2519-2528, (2017).

[22] Li, H., Chen, D., Zhang, H., Wu, C., Wang, X. Hamiltonian analysis of a hydro-energy generation system in the transient of sudden load increasing. Appl. Energ. 185, 244-253 (2017). [23] Liang, J., Yuan, X., Yuan, Y., Chen, Z., Li, Y. Nonlinear dynamic analysis and robust controller design for Francis hydraulic turbine regulating system with a straight-tube surge tank. Mech. Syst. Signal. Pr. 85, 927-946 (2017).

[24] Nagode, K., Škrjanc, I. Modelling and Internal Fuzzy Model Power Control of a Francis Water Turbine. Energies, 7(2), 874-889 (2014).

[25] Shariatkhah, M.H., Haghifam, M.R., Chicco, G., Parsa-Moghaddam, M. Modelling the Operation Strategies of Storages and Hydro Resources in Adequacy Analysis of Power Systems in Presence of Wind Farms. IET Renew. Power Gen. 10(8), 1059-1068 (2016).

[26] Xu, B.,Chen, D., Tolo, S., Patelli, E., Jiang, Y.L. Model validation and stochastic stability of a hydro-turbine governing system under hydraulic excitations. Int. J. Elec. Power 95, 156-165 (2018). 
[27] Wu, Q., Zhang, L., Ma, Z. A model establishment and numerical simulation of dynamic coupled hydraulic-mechanical-electric-structural system for hydropower station. Nonlinear Dynam. 87(1), 1-16 (2016).

[28] Al-Sharafi, A., Sahin, A.Z., Ayar, T., Yilbas, B.S. Techno-economic analysis and optimization of solar and wind energy systems for power generation and hydrogen production in Saudi Arabia. Renew. Sust. Energ. Rev. 69, 33-49 (2017).

[29] Aly, H.H.H. Dynamic modeling and control of the tidal current turbine using DFIG and DDPMSG for power system stability analysis. Int. J. Elec. Power 83, 525-540 (2016).

[30] Riasi, A., Tazraei, P. Numerical analysis of the hydraulic transient response in the presence of surge tanks and relief valves. Renew. Energy 107, 138-146 (2017).

[31] Henriques, T.A.D.J., Hedges, T.S., Owen, I., Poole, R.J. The influence of blade pitch angle on the performance of a model horizontal axis tidal stream turbine operating under wave-current interaction. Energy 102, 166-175 (2016).

[32] Kalogirou, S.A., Karellas, S., Badescu, V., Braimakis, K. Exergy analysis on solar thermal systems: A better understanding of their sustainability. Renew. Energ. 85, 1328-1333 (2016).

[33] Vaezi, M., Deldar, M., Izadian, A. Hydraulic Wind Power Plants: A Nonlinear Model of Low Wind Speed Operation. IEEE T. Contr. Syst. T. 24(5), 1-9 (2016).

[34] Shi, R.J., Fan, X.C., He, Y. Comprehensive evaluation index system for wind power utilization levels in wind farms in China. Renew. Sust. Energ. Rev. 69, 461-471 (2017). [35] Luongo, A., D’Annibale, F. Nonlinear hysteretic damping effects on the post-critical behaviour of the visco-elastic Beck's beam. Math. Mech. Solids 6, 1347-1365 (2017).

[36] Tazraei, P., Riasi, A. Quasi-Two-Dimensional Numerical Analysis of Fast Transient Flows Considering Non-Newtonian Effects. J. Fluid. Eng.-T. ASME 138(1), DOI: 10.1115/1.4031093 (2016).

[37] Trivedi, C., Gandhi, B.K., Cervantes, M.J., Dahlhaug, O.G. Experimental investigations of a model Francis turbine during shutdown at synchronous speed. Renew. Energ. 83, 828-836 (2015). [38] Thiery, F., Gustavsson, R., Aidanpää, J.O. Dynamics of a misaligned Kaplan turbine with blade-to-stator contacts. Int. J. Mech. Sci. 99, 251-261 (2015).

[39] Xu, W. Numerical analysis methods for stochastic dynamical system: Science Press, 2013. (In Chinese).

[40] Sobol, I.M. Sensitivity Estimates for Nonlinear Mathematical Models. Matem Mod 2(1), 112118 (112-118). 